\title{
An eight-year epidemiologic study based on baculovirus-expressed type-specific spike proteins for the differentiation of type I and II feline coronavirus infections
}

Ying-Ting Wang ${ }^{1}$, Ling-Ling Chueh ${ }^{1 *}$ and Cho-Hua Wan ${ }^{2^{*}}$

\begin{abstract}
Background: Feline infectious peritonitis (FIP) is a fatal disease caused by feline coronavirus (FCoV). FCoVs are divided into two serotypes with markedly different infection rates among cat populations around the world. A baculovirus-expressed type-specific domain of the spike proteins of FCoV was used to survey the infection of the two viruses over the past eight years in Taiwan.

Results: An immunofluorescence assay based on cells infected with the recombinant viruses that was capable of distinguishing between the two types of viral infection was established. A total of 833 cases from a teaching hospital was surveyed for prevalence of different FCoV infections. Infection of the type I FCoV was dominant, with a seropositive rate of $70.4 \%$, whereas $3.5 \%$ of cats were infected with the type II FCoV. In most cases, results derived from serotyping and genotyping were highly agreeable. However, 16.7\% (4/24) FIP cats and 9.8\% (6/61) clinically healthy cats were found to possess antibodies against both viruses. Moreover, most of the cats $(84.6 \%, 22 / 26)$ infected with a genotypic untypable virus bearing a type I FCoV antibody.

Conclusion: A relatively simple serotyping method to distinguish between two types of FCoV infection was developed. Based on this method, two types of FCoV infection in Taiwan was first carried out. Type I FCoV was found to be predominant compared with type II virus. Results derived from serotyping and genotyping support our current understanding of evolution of disease-related FCoV and transmission of FIP.
\end{abstract}

Keywords: Seroprevalence, Feline coronavirus, Baculovirus, Recombinant protein

\section{Background}

Feline coronavirus (FCoV), a common pathogen in cats, is an enveloped, positive-sense, single-stranded RNA virus. Together with canine coronavirus $(\mathrm{CCoV})$, transmissible gastroenteritis virus (TGEV), porcine respiratory coronavirus and human coronavirus $229 \mathrm{E}(\mathrm{HCoV}$ 229E), FCoV is classified into the genus Alphacoronavirus [1]. Two pathotypes of FCoV have been well demonstrated, i.e., feline enteric coronavirus (FECV) and feline infectious peritonitis (FIP) virus (FIPV). The former causes

\footnotetext{
* Correspondence: linglingchueh@ntu.edu.tw; chwan@ntu.edu.tw ${ }^{1}$ Graduate Institute of Veterinary Medicine, School of Veterinary Medicine, National Taiwan University, Taipei 10617, Taiwan

${ }^{2}$ Graduate Institute of Molecular and Comparative Pathobiology, School of Veterinary Medicine, National Taiwan University, Taipei 10617, Taiwan
}

mild enteric infections, and the latter causes a fatal immune-mediated disease known as FIP [2].

Infection with coronavirus is determined by the interaction between the receptor binding domain of its spike (S) protein and corresponding receptors on target cells. $S$ protein is the main determinant of cell tropism and of the induction of neutralizing antibodies [3]. FCoVs can be divided into two serotypes, types I and II, which differ in the neutralizing antibody reaction and have distinct $S$ protein sequences [4]. These two types of FCoV differ in growth characteristics in vitro. Type II FCoV is antigenically related to $\mathrm{CCoV}$ and TGEV [5]. The receptor usage of the two types of FCoV is different [6]. Feline aminopeptidase $\mathrm{N}$ was identified as a receptor for type II FCoV, but not for type I FCoV [7]. The main receptor 
for type I FCoV infection remains unclear. A feline dendritic cell-specific intercellular adhesion molecule-grabbing nonintegrin serves as a coreceptor for both type I and II FCoV [8]. Both types of FCoV can infect domestic and wild Felidae and cause FIP [2]. Seroprevalence studies for the detection of the two types of FCoV infection have been performed using various methods, and type I FCoV was found to be predominant in the field, with a seropositive rate of $83-98 \%$, whereas the type II virus accounted for only less than $10 \%$ of infections [9-11].

In this study, a type-specific partial $S$ protein-based immunofluorescence assay (IFA) was established to distinguish between the two serotypes of FCoV. The seroprevalence of FCoV in Taiwan was determined, and the correlation between the genotypes and serotypes of FCoV infection was assessed.

\section{Methods}

\section{Viruses and cells}

For the cultivation, purification and titration of recombinant baculovirus (r-virus), Spodoptera frugiperda-9 $(S f-9)$ cells were used in this study. The $S f-9$ cells were cultured in suspension at $27^{\circ} \mathrm{C}$ at densities ranging from $0.5-2 \times 10^{6}$ cells $/ \mathrm{ml}$ in HyQ SFX-Insect Media (HyClone, Logan, UT, USA) containing 5\% (v/v) fetal bovine serum (FBS) (PAA Laboratories $\mathrm{GmbH}$, Pasching, Austria) and $10 \mu \mathrm{g} / \mathrm{ml}$ gentamicin.

Felis catus whole fetus-4 (Fcwf-4) cells were used for the propagation of the type II FCoV strain NTU156 [12] and maintained in Dulbecco's modified Eagle's medium (Gibco, Grand Island, USA) supplemented with $10 \%$ FBS, $100 \mathrm{IU} / \mathrm{ml}$ penicillin and $100 \mu \mathrm{g} / \mathrm{ml}$ streptomycin in $5 \% \mathrm{CO}_{2}$ at $37^{\circ} \mathrm{C}$.

\section{Detection and genotyping of FCoV}

Several samples were collected from the cats enrolled in this study, including whole blood, plasma, swab samples (rectal, nasal, oral and conjunctival swabs), body effusions and internal organ samples, and were screened for FCoV by reverse transcription-nested polymerase chain reaction (RT-nPCR) [13]. FCoV-positive samples were subsequently subjected to genotyping of the virus according to the procedures reported by Addie et al. [14].

\section{Clinical samples}

To further characterize the correlation between the serotype of the infection and FIP, plasma samples from 43 pathologically confirmed, naturally occurring FIP cases and 30 suspected FIP cases, which were FCoV RT-nPCR positive in effusions with/without an IFA signal present in macrophages [15], were further tested. Moreover, to evaluate the seroprevalence of different types of $\mathrm{FCoV}$ infection in Taiwan, plasma samples from 760 clinically healthy cats were collected around the island of Taiwan from 1996-2013. All samples were stored at $-20^{\circ} \mathrm{C}$ until analysis. An ethical approval was not required as this study was performed retrospectively and samples of diseased animals were routinely submitted to the veterinary diagnostic laboratory.

\section{Detection of anti-FCoV antibody}

For the screening of anti-FCoV antibody-positive samples, a type II FCoV-based IFA was used in the present study. Fcwf-4 cells seeded in a 96-well plate were infected with the type II FCoV strain NTU156 at a multiplicity of infection (MOI) of 0.01 and incubated for 18 hours. Once each well contained $30 \%$ infected cells and $70 \%$ uninfected cells as an internal negative control, the infected cells were fixed with cold 50/50 acetone/ methanol (v/v) for ten minutes. A plasma sample diluted 1:40 with PBS was transferred to the well and allowed to incubate for 60 minutes at room temperature. Subsequently, the cells were washed 5 times with PBS, and fluorescein isothiocyanate (FITC)-conjugated goat anticat IgG (1:1000 dilution) was added to each well for a 60-minute incubation at room temperature. When syncytial cells, which are a typical cytopathic effect (CPE) of FCoV infection, showed fluorescent signals that were interpreted as positive, the cat was considered to be infected with FCoV. Positive samples were further serotyped.

\section{Amplification, cloning and expression of type-specific $S$ genes}

Because S protein is the key determinant of the discrimination of serotypes, a region specific to the two types of FCoV was chosen for analysis. The type I FCoV strain NTU2 (GenBank: DQ160294) and the type II FCoV strain NTU156 (GenBank: GQ152141) were employed in this study. Two pairs of primers based on the RBD region of the $S$ gene, with the restriction site EcoR1, Kpn1 or BamH1, were designed (FCoV-I pRBD F: 5'-gaattcat gttttactctgctagtatgctt-3' and FCoV-I pRBD R: 5'-ggtacctt aaccagctgtgcctttg-3'; FCoV-II pRBD F: 5'-ggatccatgcctgt agcctcgagtgacg-3' and FCoV-II pRBD R: 5'-ggtaccttagtg aggaccactattatcagac-3') and used to amplify the targeted region of the $S$ gene. This region was 510 and 513 nucleotides in length for type I and II FCoV, respectively. The amplified products were cloned into the pFastBac ${ }^{\mathrm{TM}} \mathrm{HT}$ vector using the Bac-to-Bac Baculovirus Expression System (Invitrogen srl, Milan, Italy) following the manufacturer's instructions. The FCoV-I pRBD-bacmid and FCoV-II pRBD-bacmid were used to transfect $S f-9$ cells to obtain r-viruses (rFCoV-I and rFCoV-II) containing an N-terminal $6 \times$ histidine tag.

\section{Confirmation of recombinant proteins}

Sf-9 cells were infected with rFCoV-I or rFCoV-II at different MOI values, and cell pellets from different post-infection 
times were lysed for Western blotting analysis. The expressed recombinant proteins were resolved by SDSPAGE and transferred to PVDF membranes. The membranes were blocked using $5 \%(\mathrm{w} / \mathrm{v})$ non-fat dry milk for two hours at room temperature, followed by incubation with an anti-histidine mouse monoclonal antibody $(\mathrm{mAb})$ (Invitrogen srl, Milan, Italy) at room temperature. After washes in PBS-Tween 20, each membrane was incubated with horseradish peroxidase (HRP)-conjugated goat anti-mouse IgG antibody (Jackson ImmunoResearch Laboratories, PA, USA). The membranes were developed with 3,3,5,5'-tetramethylbenzidine (TMB) substrate (Kirkegaard \& Perry Laboratories, MD, USA).

\section{Serotyping}

To differentiate the serotypes of infection, a novel typespecific IFA using rFCoV-I- or rFCoV-II -infected $S f-9$ cells was established. $S f-9$ cells seeded in a 96 -well plate were infected with either rFCoV-I or $\mathrm{rFCoV}$-II at an MOI of 0.5. After 72 hours of incubation, the infected cells were fixed with cold acetone/methanol. Two-folddiluted plasma samples (from 1:50 to 1:1600) from cats with FIP cats were transferred into the wells (rFCoV-Ior and rFCoV-II -infected $S f-9$ cells or mock infection) and incubated for 60 minutes at room temperature. After washing 5 times with PBS, 1000-fold-diluted FITCconjugated goat anti-cat IgG was added to each well for 60 minutes at room temperature. FCoV-positive sera collected from cats without FIP were diluted 1:100 and applied to the IFA system as above for serotyping analysis. Two polyclonal antisera (VMRD, Pullman, WA, USA) against type I and II FCoV were used as referenced positive-control sera. Two sera from specific pathogenfree (SPF) cats were used as negative-control sera. The serotype of each $\mathrm{FCoV}$ infection was identified based on rFCoV-I- or rFCoV-II-infected Sf-9 cells (rRBD-1 and rRBD-II) showing a fluorescent signal after IFA staining with 200-fold-diluted or higher plasma samples from cats with FIP and 100-fold-diluted samples from healthy cats.

\section{Neutralization test (NT)}

To further compare the assay established in this study to a gold standard method, plasma samples from FIP confirmed animals were examined by both NT test and the type-specific IFA. Heat inactivated plasma samples were diluted 10 and 100 fold followed by a two fold serial dilution up to 1600 fold. Subsequently, diluted sample were mixed with an equal volume of a type II $\mathrm{FCoV}$ strain NTU156 containing $100 \mathrm{PFU} / 50 \mu \mathrm{l}$ and incubated at $37^{\circ} \mathrm{C}$ for $1 \mathrm{~h}$. Each mixture was then inoculated onto Fcwf- 4 cells monolayer in a 96 well microplate at $37^{\circ} \mathrm{C}$ for 3 days. The reciprocal of the highest dilution of antibody that completely inhibited viral CPE formation was expressed as the virus-neutralizing titer.

\section{Results}

Prevalence of FCoV in Taiwan

All of the samples from the 43 confirmed FIP cases and 30 suspected FIP cases were FCoV seropositive. In addition to the cats with FIP, a total of 760 clinically healthy cats collected from 26 veterinary hospitals in 6 cities in Taiwan over 8 years were enrolled in this study, 28.2\% (214/760) of which were positive for FCoV. The overall prevalence of FCoV in Taiwan was 34.5\% (287/833) (Table 1).

\section{Amplification of $S$ region based on RBD of type I and II FCoV for type-specific protein expression}

To distinguish between the serotypes of FCoV infection, a novel type-specific IFA was established. To express the protein fragment that is antigenically distinct between type I and II FCoV, the type-specific region of the $S$ gene, based on the putative RBD of type II FCoV and the corresponding region of type I FCoV, was selected. The expressed regions were located from amino acids no. 523 to no. 692 and no. 508 to no. 678 of the S proteins of type I and II FCoV, respectively (Figure 1a). The partial $S$ genes of different types of FCoV were amplified, directionally cloned into the pFastBac ${ }^{\mathrm{Tm}} \mathrm{HT}$ vector and used to generate r-viruses, i.e., rFCoV-I and rFCoV-II. Recombinant proteins with the expected size (approximately $23 \mathrm{kDa}$ for type I and type II FCoV) were identified (Figure 1b).

\section{Establishment and confirmation of type-specific IFA}

The specificity of the type-specific IFA was verified using plasma samples from the confirmed type I or II FCoVinfected cats or from SPF cats. Both recombinant proteins could be detected by the anti-histidine mAb, with a positive signal located in the cytoplasm. In contrast, no fluorescent signal was observed while using sera from the SPF cats (Figure 2). The plasma from type I FCoVinfected cats could specifically react with rRBD-I, but not with rRBD-II, and vice versa. While using the plasma samples from dually FCoV-infected cats with FIP, positive signals could be observed for both types of $r$-RBD (Figure 2). Based on these data, the specificity of both recombinant proteins was confirmed. To further validate the assay, the serotyping result derived from typespecific IFA was compared to a gold standard, NT.

Table 1 Prevalence of FCoV serotypes I and II in cats with different disease statuses in Taiwan

\begin{tabular}{llllll}
\hline Status & \multicolumn{3}{l}{ Serotype $\mathbf{n}(\%)$} & Total \\
\cline { 2 - 5 } & $\mathbf{I}$ & $\mathbf{I I}$ & $\mathbf{I} / \mathbf{I I}$ & Untypable & \\
\hline FIP & $29(67.4)$ & $3(7.0)$ & $11(25.6)$ & $0(0)$ & 43 \\
FIP-suspected & $24(80.0)$ & $2(6.7)$ & $3(10.0)$ & $1(3.3)$ & 30 \\
Non-FIP & $149(69.7)$ & $5(2.3)$ & $37(17.3)$ & $23(10.7)$ & 214 \\
Total & $202(70.4)$ & $10(3.5)$ & $51(17.8)$ & $24(8.3)$ & 287 \\
\hline
\end{tabular}



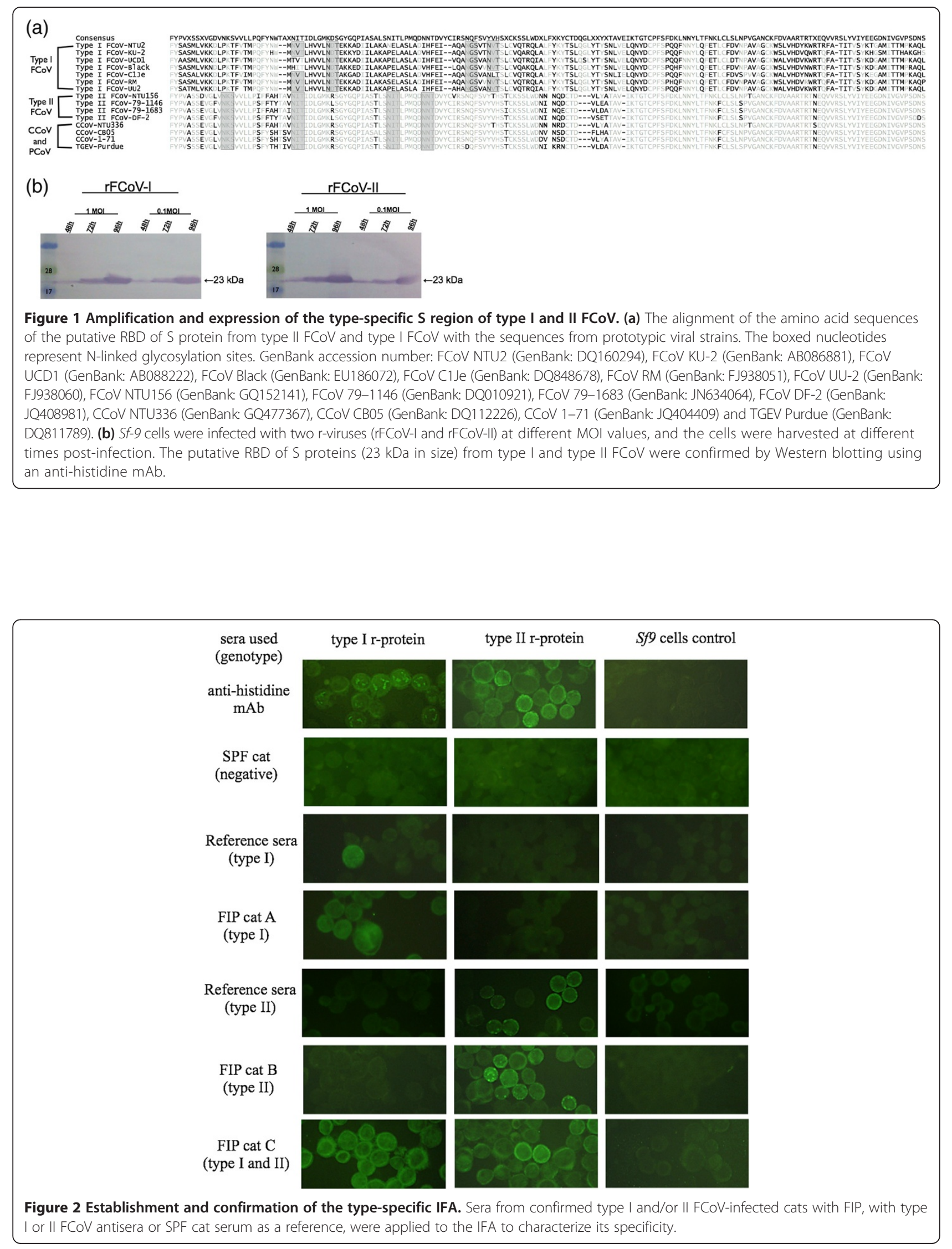
Plasma samples from FIP animals bearing antibody against rRBD-II $(\geq 400 \times)$ were found to possess a relatively high NT titer $(\geq 800 \times)$ against type II FCoV, indicating a type II FIPV infection (5/5). On the other hand, samples bearing antibody solely against rRBD-I $(200 \times-$ $1600 \times)$ showed barely detectable NT titer $(\leq 10 \times)$ against type II virus, indicating a type I FIPV infection (19/19) (Table 2). The results show that serotypes determined by the type-specific IFA test are highly agreeable with NT test.

\section{Association between FCoV genotype and serotype}

Among seropositive cats, $70.4 \%(202 / 287)$ of cats had antibodies specific to rRBD-I, whereas $3.5 \%$ (10/287) had antibodies to rRBD-II, and $17.8 \%(51 / 287)$ reacted to both types (Table 1). Infection with serotype I FCoV appeared to be dominant in both the FIP and the non-FIP groups (Table 1).

To evaluate the correlation between the serotype and the genotype of the infection, plasma samples collected from type I or II FCoV-infected cats with FIP were analyzed. In comparison of results derived from serotyping and genotyping, the serotype of FCoV was found highly agree with the genotype in most cases. For the cats with type I FIP, most $(17 / 20,85 \%)$ had antibodies specific to rRBD-I, except for three cats (FIP-18, FIP-19 and FIP-20) (Table 2). Of the solely type II-infected cats with FIP, four cats (FIP-21 to FIP-24) had titers specifically against rRBD-II, but only one of these cats (FIP-24) possessed antibodies against rRBD-I as well (Table 2).

Of the cats without FIP with type I FCoV detected by RT-nPCR, 78.1\% (25/32) had antibodies against r-RBD-I, and $9.4 \%(3 / 32)$ were positive for antibodies against both types. Additionally, the serotypes of four samples failed to be identified. Moreover, three plasma samples collected from healthy cats with type II FCoV detected in fecal samples were used for serotyping [16]. All three samples were FCoV seropositive, but only one was identified as infected by both types of FCoV. Of those cats infected with the FCoVs that failed to be genotyped, $84.6 \%(22 / 26)$ possessed antibodies against type I FCoV (Table 3).

\section{Discussion}

In this study, an FCoV type-specific, recombinant proteinbased IFA was established. The expressed recombinant $\mathrm{RBD}$ region of the type II FCoV S protein, bearing onetenth of the authentic $S$ protein critical in both virus neutralization and cell attachment, is highly conserved among FCoV, TGEV and CCoV [17]. The alignment of the amino acid sequences of this region revealed relative conservation among prototypic viral strains within the same serotype (i.e., $86.8-95.4 \%$ and $91.4-98.3 \%$ of type I and II FCoV, respectively) but were distinct between
Table 2 Genotype, serotype and NT titer against FCoV from FIP cats

\begin{tabular}{|c|c|c|c|c|}
\hline \multirow[t]{2}{*}{ Case } & \multicolumn{2}{|l|}{ Genotype $^{a}$} & \multirow{2}{*}{$\begin{array}{l}\text { Serotype } \\
\text { (IFA titer) }\end{array}$} & \multirow{2}{*}{$\begin{array}{l}\text { NT } \\
\text { titer }^{\text {b }}\end{array}$} \\
\hline & $\begin{array}{l}\text { Typing I } \\
\text { (specimen) }\end{array}$ & $\begin{array}{l}\text { Typing II } \\
\text { (specimen) }\end{array}$ & & \\
\hline FIP-1 & As & & I (400) & $\leq 10$ \\
\hline FIP-2 & As & & I (800) & 10 \\
\hline FIP-3 & As & & I (800) & $\leq 10$ \\
\hline FIP-4 & As & & I (800) & \\
\hline FIP-5 & $B, R$ & & I ( $\geq 1600)$ & \\
\hline FIP-6 & Lu & & I (400) & \\
\hline FIP-7 & $B, R$ & & I (800) & $\leq 10$ \\
\hline FIP-8 & $\mathrm{R}$ & & I (800) & \\
\hline FIP-9 & B & & I (800) & \\
\hline FIP-10 & $\mathrm{R}$ & & I (400) & \\
\hline FIP-11 & PI & & I (400) & 10 \\
\hline FIP-12 & $\mathrm{R}, \mathrm{Br}$ & & I (800) & $\leq 10$ \\
\hline FIP-13 & $\mathrm{R}$ & & I (400) & 10 \\
\hline FIP-14 & Lu & & I (400) & \\
\hline FIP-15 & As & & I ( $\geq 1600)$ & $\leq 10$ \\
\hline FIP-16 & As & & I (200) & \\
\hline FIP-17 & As & & I (400) & 10 \\
\hline FIP-18 & $\mathrm{R}$ & & I (400)/II (400) & \\
\hline FIP-19 & As, $R$ & & | (400)/II (400) & \\
\hline FIP-20 & As & & I ( $\geq 1600) /||(400)$ & \\
\hline FIP-21 & & $A s, B, R$ & $\|(\geq 1600)$ & \\
\hline FIP-22 & & $\mathrm{Br}$ & $\|(\geq 1600)$ & 400 \\
\hline FIP-23 & & $\mathrm{Pl}, \mathrm{Li}, \mathrm{Ki}$ & $\|(\geq 1600)$ & $\geq 1600$ \\
\hline FIP-24 & & As, CSF, Ki & $|(\geq 1600) /| \mid(\geq 1600)$ & 800 \\
\hline FIP-25 & & & I $(\geq 1600)$ & 10 \\
\hline FIP-26 & & & I (400) & $\leq 10$ \\
\hline FIP-27 & & & I (400) & 10 \\
\hline FIP-28 & & & I (800) & $\leq 10$ \\
\hline FIP-29 & & & | (200)/|| (400) & $\geq 1600$ \\
\hline FIP-30 & & & I (800)/II ( $\geq 1600)$ & $\geq 1600$ \\
\hline FIP-31 & & & I (400) & $\leq 10$ \\
\hline FIP-32 & & & I (400) & $\leq 10$ \\
\hline FIP-33 & & & I (800) & $\leq 10$ \\
\hline FIP-34 & & & I $(\geq 1600)$ & 10 \\
\hline FIP-35 & & & I (800) & $\leq 10$ \\
\hline FIP-36 & & & I (400) & $\leq 10$ \\
\hline
\end{tabular}

${ }^{a}: R$, Rectal swabs; As, Ascites; Pl, Pleural effusions; B, Blood; CSF, Cerebrospinal fluid; Li, Liver; Lu, Lung; Ki, Kidney; Br, Brain.

${ }^{b}$ : NT titer against a type II FIPV.

different serotypes (20.7-23.0\%) (Figure 1a). As the expressed partial S proteins contained four N-linked glycosylation sites for both type I (551-NVT-553, 559NDT-561, 591-NGS-593 and 596-NVT-598) and type 
Table 3 Correlation between serotype and genotype in FCoV antibody-positive animals without FIP

\begin{tabular}{llllllll}
\hline RT-nPCR & Genotype & \multicolumn{3}{l}{ Serotype $\mathbf{n}(\%)$} & Total \\
\cline { 3 - 6 } & & $\mathbf{I}$ & $\mathbf{~ I}$ & $\mathbf{l} / \mathbf{l}$ & Negative & \\
\hline Positive & I & $25(78.1)$ & $0(0)$ & $3(9.4)$ & $4(12.5)$ & 32 \\
& II & $0(0)$ & $0(0)$ & $1(33.3)$ & $2(66.7)$ & 3 \\
& UT & $22(84.6)$ & $1(3.8)$ & $2(7.7)$ & $1(3.8)$ & 26 \\
& NA & $23(56.1)$ & $1(2.4)$ & $13(31.7)$ & $4(9.7)$ & 41 \\
Negative & & $24(75)$ & $1(3.1)$ & $3(9.4)$ & $4(12.5)$ & 32 \\
NA & $55(68.8)$ & $2(2.5)$ & $15(18.7)$ & $8(10)$ & 80 \\
Total & $149(69.7)$ & $5(2.3)$ & $37(17.3)$ & $23(10.7)$ & 214 \\
\hline
\end{tabular}

UT: Untypable.

$N A$ : Not available.

II (520-NKS-522, 536-NIT-539, 558-NIT-560 and 566NNT-568) FCoV (Figure 1a), the baculovirus expression system was chosen to provide post-translational modification and complex folding, including glycosylation $[18,19]$. A similar strategy was applied to severe acute respiratory syndrome (SARS)-CoV, and the recombinant RBD maintained authentic antigenicity that induced a strong RBD-specific antibody response [20]. In addition, baculovirus-expressed, truncated SARSCoV S protein-based IFAs were found to be highly sensitive and specific compared with conventional whole virus-based IFAs [21,22].

Based on different testing methods, the prevalence of $\mathrm{FCoV}$ in field cats varies among countries, e.g., $50 \%$ in Switzerland [10], 34\% in Australia [23], 22\% in Japan [11] and $13.7 \%$ in Korea [24]. In the present study, FCoV-specific antibodies detected by IFA based on proteins derived from a local FCoV isolate revealed a seroprevalence of $34.5 \%$. Previous studies revealed that $>80 \%$ of seropositive cats are suspected to be infected with type I FCoV [9-11]. In the present study, $70.4 \%$ of local cats were infected with type I FCoV. Infection with type II FCoV in Taiwan $(21.3 \%, 61 / 287)$ is higher than in other countries, i.e., $4.4 \%$ in Switzerland and $10.1 \%$ and 2\% in Japan in 1992 and 2007, respectively. The dense population and close contact between cats and other animals in Taiwan could be reasons contributing to the higher rate of recombination between FCoVs and CCoVs or other alphacoronaviruses, leading to a relatively high type II FCoV infection rate. This relatively high antibody titer against type II virus might also result from other alphacoronavirus infection, as feline cells are susceptible to infection with $\mathrm{FCoV}, \mathrm{CCoV}$, TGEV and $\mathrm{HCoV}-229 \mathrm{E}$ [25] and given that seroconversion was observed in cats experimentally infected with CCoV [26], TGEV [27] or HCoV-229E [28].

In a prior study, a competitive ELISA was used to discriminate the serotype of infection [11]. However, certain sera could not be typed once inhibition reached $30-80 \%$.
In the present study, serotypes were determined by the direct observation of a fluorescent signal specifically indicating two types of recombinant protein, which decreased the ambiguity. In another IFA study using type I or type II FCoV-infected cells, 23\% of cats displayed equal titers against type I and II FCoV. The phenomenon was suggested by the authors to result either from antibodies against common antigenic epitopes in other structural protein or from co-infection with the two viruses [10]. Our type-specific $S$ protein-based IFA can avoid the sharing of common antigenicity, and co-infection can be readily identified.

This is the first report to correlate viral infection with the specific antibody evoked. We compared the serotypes and the genotypes of FCoV-infected animals. Most type I FCoV-infected cats with FIP harbored anti-type I FCoV antibodies, and three of them displayed antibodies against both types of $\mathrm{FCoV}$, indicating co-infection with $\mathrm{FCoV}$ and/or other CoVs. Additionally, one cat with type II FIP (FIP-24) displayed an antibody response to type I and II FCoV simultaneously. This finding matches the recombination theory that states that type II FCoV arises from the mutation of type I FCoV. However, we found that three cats with type II FIP possessed antibodies solely against type II FCoV. Among those cats, FIP-23 (cat 11) was living in a shelter that had experienced a recent FIP outbreak caused by type II FCoV [29]. The presence of antibodies solely against type II FCoV in cat FIP-23 provides an additional clue about the horizontal transmission of type II FIP. In the case of cat FIP-22, sequencing analysis of the C-terminal one-third of the viral genome indicated a virus bearing high resemblance to $\mathrm{CCoV}$, but not to $\mathrm{FCoV}$. Combining the serological and genetic findings, this FIP could have resulted from a $\mathrm{CCoV}$ infection. Further genetic analysis regarding this speculation is currently under investigation.

Among healthy cats with untypable FCoV, 84.6\% were found to have a type I FCoV infection. Although the serotype of the antibodies detected did not always match the virus present at the time of sampling, infection with FCoVs, and especially with type I, is persistent and can last for several years in a multicat environment $[14,30]$. Moreover, type I virus has been reported to be more genetically diverse than type II virus in the genotyped region, and this diversity might hinder PCR amplification [16]. Despite the better distinguishability, $8.3 \%$ of the cats in the current study possessed anti-FCoV antibodies that could not be serotyped. This issue could have been due to the lower antibody titers against FCoV, or polymorphisms may exist in the target region in $\mathrm{S}$ protein.

FCoV antibody titers when accurately performed are thought to be of some value in distinguishing enteric infection from FIP. Cats with IFA titers $\geq 1: 3200$ are highly suggestive of FIP [31]. In our study using the serotyping 
method established, type-specific FCoV antibody could be titrated and the titer in some of our FIP cats reached relatively high level as well $(\geq 1: 1600)$. Our recent study revealed that the infection of serotype II FCoV correlated significantly with the occurrence of FIP [16]. Also horizontal transmission of a serotype II virus was clearly demonstrated to responsible for a FIP outbreak [29]. Continuous survey of the antibodies against two serotype of $\mathrm{FCoV}$, especially in the multi-cat environment could help in identifying the invasion of any type II FCoV hence isolating the animals to prevent future FIP occurrence.

\section{Conclusions}

In conclusion, compared with the results of previous studies, we present a relatively simple serotyping method to discriminate between two types of FCoV infection. Based on this method, type I FCoV was found to be predominant compared with type II in Taiwan. This survey also provided clues supporting the evolution and horizontal transmission of type II FIPV. The epidemiological survey also provided valuable information for disease control and vaccine development.

\section{Competing interests}

The authors declare that they have no competing interests.

\section{Authors' contributions}

YTW performed the sampling and preparation, FCoV detection, genotyping, type-specific IFA development, anti-FCoV antibody detection, serotyping and further analysis and prepared the manuscript. LLC conceived the study, participated in study design and coordination and contributed to the preparation of the manuscript. CHW participated in study design, supervised the type-specific IFA development and contributed to the preparation of the manuscript. All authors read and approved the final manuscript.

\section{Acknowledgments}

The authors would like to thank Prof. Lela K. Riley from the Research Animal Diagnostic Laboratory of the University of Missouri-Columbia for kindly providing the Sf-9 cell line. We are grateful to Prof. Peter J. M. Rottier from Utrecht University for supplying the Fcwf-4 cells and the sera from SPF cats. We acknowledge Prof. Ching-Ho Wang from National Taiwan University for providing the vectors and the technical assistance of Yung-Hui Chang.

Received: 26 March 2014 Accepted: 11 August 2014

Published: 15 August 2014

\section{References}

1. Masters PS, Perlman S: Coronaviridae. In Fields virology. 6th edition. Edited by Knipe DM, Howley PM, Cohen Jl, Griffin DE, Lamb RA, Martin MA, Racaniello VR, Roizman B. Philadelphia: Lippincott Williams \& Wikins; 2013:826-854

2. Pedersen NC: A review of feline infectious peritonitis virus infection: 1963-2008. J Feline Med Surg 2009, 11:225-258.

3. Du L, He Y, Zhou Y, Liu S, Zheng BJ, Jiang S: The spike protein of SARS-CoV-a target for vaccine and therapeutic development. Nat Rev Microbiol 2009, 7:226-236.

4. Hartmann K: Feline infectious peritonitis. Vet Clin North Am Small Anim Pract 2005, 35:39-79.

5. Herrewegh AA, Smeenk I, Horzinek MC, Rottier PJ, de Groot RJ: Feline coronavirus type II strains 79-1683 and 79-1146 originate from a double recombination between feline coronavirus type I and canine coronavirus. J Virol 1998, 72:4508-4514.
6. Hohdatsu T, Izumiya Y, Yokoyama Y, Kida K, Koyama H: Differences in virus receptor for type I and type II feline infectious peritonitis virus. Arch Virol 1998, 143:839-850.

7. Regan AD, Ousterout DG, Whittaker GR: Feline lectin activity is critical for the cellular entry of feline infectious peritonitis virus. J Virol 2010, 84:7917-7921.

8. Van Hamme E, Desmarets L, Dewerchin HL, Nauwynck HJ: Intriguing interplay between feline infectious peritonitis virus and its receptors during entry in primary feline monocytes. Virus Res 2011, 160:32-39.

9. Shiba N, Maeda K, Kato H, Mochizuki M, Iwata H: Differentiation of feline coronavirus type I and II infections by virus neutralization test. Vet Microbiol 2007, 124:348-352.

10. Kummrow M, Meli ML, Haessig M, Goenczi E, Poland A, Pedersen NC, Hofmann-Lehmann R, Lutz H: Feline coronavirus serotypes 1 and 2: seroprevalence and association with disease in Switzerland. Clin Diagn Lab Immunol 2005, 12:1209-1215.

11. Hohdatsu T, Okada S, Ishizuka Y, Yamada H, Koyama H: The prevalence of types I and II feline coronavirus infections in cats. J Vet Med Sci 1992, 54:557-562

12. Lin CN, Su BL, Wu CW, Hsieh LE, Chueh LL: Isolation and identification of a novel feline coronavirus from a kitten with naturally occurring feline infectious peritonitis in Taiwan. Taiwan Vet J 2009, 35:145-152.

13. Herrewegh AA, de Groot RJ, Cepica A, Egberink HF, Horzinek MC, Rottier PJ: Detection of feline coronavirus RNA in feces, tissues, and body fluids of naturally infected cats by reverse transcriptase PCR. J Clin Microbiol 1995, 33:684-689.

14. Addie DD, Schaap IA, Nicolson L, Jarrett O: Persistence and transmission of natural type I feline coronavirus infection. J Gen Virol 2003, 84:2735-2744.

15. Litster AL, Pogranichniy R, Lin TL: Diagnostic utility of a direct immunofluorescence test to detect feline coronavirus antigen in macrophages in effusive feline infectious peritonitis. Vet J 2013, 198:362-366.

16. Lin CN, Su BL, Wang CH, Hsieh MW, Chueh TJ, Chueh LL: Genetic diversity and correlation with feline infectious peritonitis of feline coronavirus type I and II: A 5-year study in Taiwan. Vet Microbiol 2009, 136:233-239.

17. Corapi WV, Darteil RJ, Audonnet JC, Chappuis GE: Localization of antigenic sites of the $S$ glycoprotein of feline infectious peritonitis virus involved in neutralization and antibody-dependent enhancement. J Virol 1995, 69:2858-2862.

18. Cox MM: Recombinant protein vaccines produced in insect cells. Vaccine 2012, 30:1759-1766.

19. Aucoin MG, Mena JA, Kamen AA: Bioprocessing of baculovirus vectors: a review. Curr Gene Ther 2010, 10:174-186.

20. Du L, Zhao G, Chan CC, Sun S, Chen M, Liu Z, Guo H, He Y, Zhou Y, Zheng BJ, Jiang S: Recombinant receptor-binding domain of SARS-CoV spike protein expressed in mammalian, insect and E. coli cells elicits potent neutralizing antibody and protective immunity. Virology 2009, 393:144-150.

21. Manopo I, Lu L, He Q, Chee LL, Chan SW, Kwang J: Evaluation of a safe and sensitive Spike protein-based immunofluorescence assay for the detection of antibody responses to SARS-CoV. J Immunol Methods 2005, 296:37-44.

22. He Q, Manopo I, Lu L, Leung BP, Chng HH, Ling AE, Chee LL, Chan SW, Ooi EE, Sin YL, Ang B, Kwang J: Novel immunofluorescence assay using recombinant nucleocapsid-spike fusion protein as antigen to detect antibodies against severe acute respiratory syndrome coronavirus. Clin Diagn Lab Immunol 2005, 12:321-328.

23. Bell ET, Toribio JA, White JD, Malik R, Norris JM: Seroprevalence study of feline coronavirus in owned and feral cats in Sydney, Australia. Aust Vet $J$ 2006, 84:74-81.

24. An DJ, Jeoung HY, Jeong W, Park JY, Lee MH, Park BK: Prevalence of Korean cats with natural feline coronavirus infections. Virol I 2011, 8:455.

25. Tusell SM, Schittone SA, Holmes KV: Mutational analysis of aminopeptidase $\mathrm{N}$, a receptor for several group 1 coronaviruses, identifies key determinants of viral host range. J Virol 2007, 81:1261-1273.

26. Stoddart CA, Barlough JE, Baldwin CA, Scott FW: Attempted immunisation of cats against feline infectious peritonitis using canine coronavirus. Res Vet Sci 1988, 45:383-388.

27. Reynolds DJ, Garwes DJ: Virus isolation and serum antibody responses after infection of cats with transmissible gastroenteritis virus. brief report. Arch Virol 1979, 60:161-166.

28. Barlough JE, Johnson-Lussenburg CM, Stoddart CA, Jacobson RH, Scott FW: Experimental inoculation of cats with human coronavirus 229E and 
subsequent challenge with feline infectious peritonitis virus. Can $J$ Comp Med 1985, 49:303-307.

29. Wang YT, Su BL, Hsieh LE, Chueh LL: An outbreak of feline infectious peritonitis in a Taiwanese shelter: epidemiologic and molecular evidence for horizontal transmission of a novel type II feline coronavirus. Vet Res 2013, 44:57.

30. Pedersen NC, Allen CE, Lyons LA: Pathogenesis of feline enteric coronavirus infection. J Feline Med Surg 2008, 10:529-541.

31. Pedersen NC: An update on feline infectious peritonitis: diagnostics and therapeutics. Vet J 2014, 201:133-141.

doi:10.1186/s12917-014-0186-7

Cite this article as: Wang et al:: An eight-year epidemiologic study based on baculovirus-expressed type-specific spike proteins for the differentiation of type I and II feline coronavirus infections. BMC Veterinary Research 2014 10:186.

\section{Submit your next manuscript to BioMed Central and take full advantage of:}

- Convenient online submission

- Thorough peer review

- No space constraints or color figure charges

- Immediate publication on acceptance

- Inclusion in PubMed, CAS, Scopus and Google Scholar

- Research which is freely available for redistribution 